\title{
Need for Bioplastics and Role of Biopolymer PHB: A Short Review
}

\section{Bharti SN* and Swetha G}

Lovely Professional University, Punjab, India

\begin{abstract}
$\mathrm{PHB}$, a biodegradable polymer that can be synthesized by bacterial systems under certain conditions or as a biosynthetic product, which has significant characters as that of synthetic polymers while being eco-friendly. The key for research lies in its properties like biodegradable, durable, temperature resistant, non- pollution causing polymer. This simple human friendly polymer belongs to a huge class of biopolymers by PHA, stands for Poly hydroxy Butarates, well known for their physico-chemical properties as natural polymers.

It's high time, needful now to protect natural environment and depend the minimum on non renewable resources. In this context, Synthetic plastics stand in the top- occupying the major non-recyclable, non biodegradable material on the planet. Many polymers in nature can meet these demands, research in this regard with the target to replace the petroleum plastics with natural, biodegradable, recyclable plastics. Of all, family of PHA has gained attention with its characteristic features and competitive as that of synthetic plastics. This short review focuses on few process parameters, use of better and cheap substrate possible, challenges in process development for commercialization of bioplastic production.
\end{abstract}

Keywords: Biodegradable polymer; Synthetic polymer; Recyclable plastic

Abbrevations: PHA: Poly Hydroxy Alkanoate; PHB: Poly Hydroxy Butarate

\section{Introduction}

Bioplastics are defined as polymers of biomass mainly carbon based compounds. The major environment concern these days is increasing non degradable waste on planet and replenishing reserves of non renewable fossil fuels. The major environment concerns behind extensive synthetic plastics usage are its biodegradability, and production of toxins while its degradation. Therefore there is an absolute of need for "eco-friendly" plastics. PHA's, the class of Alkanoates, closely resemble synthetic plastics which make them as good alternate. These are most studied Bioplastics. They get accumulated in microbes as storage materials under certain conditions. These polymers can be extracted and can be easily moulded.

PHB is Poly hydroxy butarate belongs to family of Poly hydorxy alkanoates is class of bio polymers. Their properties resemble that of synthetic plastics however the most attracting property of them is production and degradation which is contradictory to synthetic plastics. Since decades plastics being more commercial manufacturing polymer, got accumulated on planet raising a serious question of degradation, recycling cost. Also non renewable carbon sources like fossil fuels, petroleum being the starting material for production, serious crisis of non renewable resources is seen in near future. Plastic has become a part of everyday life due to their properties like flexibility, strength, versatile, easily tailored into thin films to huge containers, durable. But in the environment it is creating unsolved problems like pollution and waste.

The drawback lies in overcoming the high production cost for Bioplastics. Research shows that this can be overcome by using natural substrates and production procedures rather going for complex ones. Many microbes under stress conditions produce additional substances and they get accumulated as storage materials in their cells.

\section{Efficient use of microbial accumulates}

For the organisms that can store $\mathrm{PHB}$, is a primary assimilated carbon. When the cells are subjected to nutrient stress by using excess carbon with a deficient nutrient, synthesis of PHB occurs in cells. It clearly indicates that carbon and few chemical sources like phosphate, iron, magnesium, oxygen are controlling factors for $\mathrm{PHB}$ production. Other fermentation parameters like $\mathrm{pH}$, temperature are physical factors that affect PHB production. There are different polymers that are being extensively studied for substituting synthetic plastic with biodegradable plastic. Few of them are polyhydroxyalkanoates (PHAs), polylactide (PLA), poly ( $\varepsilon$-caprolactone) (PCL), poly (p-dioxanone) (PPDO) and poly (butylene succinate) (PBS). Of all, PHAs have gained significance for their properties and feasibility. Remarkable investigation is underway in order to drift down the high production costs. Several things have been taken into consideration. They can be

-Developing recombinant strains

-Improving the fermentation process

-Betterment in downstream processing steps

-Improving product recovery steps

These are few handling techniques by which production cost can be substantially brought down.

Further in the production cost there has the remarkable decrease is by using inexpensive carbon source as substrate. Different fermentable substrates can be used for different microbial strains.

With the advancement of recombinant DNA technology, engineered species are preferred for industrial bioplastic production.

"Corresponding author: Suraj Narayan Bharti, Lovely Professional University, Punjab, India, Tel: +918102243931; E-mail: surajbharti915@gmail.com

Receive February 21, 2015; Accepted February 28, 2016; Published March 05 2016

Citation: Bharti SN, Swetha G (2016) Need for Bioplastics and Role of Biopolymer PHB: A Short Review. J Pet Environ Biotechnol 7: 272. doi:10.4172/21577463.1000272

Copyright: $\odot 2016$ Bharti SN, et al. This is an open-access article distributed under the terms of the Creative Commons Attribution License, which permits unrestricted use, distribution, and reproduction in any medium, provided the original author and source are credited. 
Citation: Bharti SN, Swetha G (2016) Need for Bioplastics and Role of Biopolymer PHB: A Short Review. J Pet Environ Biotechnol 7: 272. doi:10.4172/2157-7463.1000272

Few inexpensive substrates well investigated so far are Sugar cane molasses, corn syrup, corn steep liquor (also in combination), starch based products, paperwaste, Acid hydrolysed malt waste, diary whey [1].

\section{Material and Methods}

\section{PHB production}

PHB belongs to class of PHA, polyesters of hydroxy alkonates. They accumulate as monomer inclusions in microbial cells. This often occurs in both gram positive and gram negative bacteria under nutrient imbalance condition. The cells store granules of polymer. The amount of polymer accumulation depends on the microorganism.

Properties of PHB [2].

- PHB ecofriendly, biodegradable.

- It can be decomposed into water and $\mathrm{CO}_{2}$ by microorganisms

- They are chain of 14 monomeric units.

- Molecular weight varies from $2-3 \times 10^{3} \mathrm{kDa}$. This again depends on capacity of microorganism to store the produced polymer.

- Can be a good substitute for synthetic plastic

- Can be produced from non replenishing sources

Poly hydroxy alkanoates can be further classified into different monomers based on the carbon chain attached. Short Length (contain 5 carbon PHA units), Medium Length (contain 6-14 carbon PHA units), Long Length (contain more than 14 carbon PHA) [3] (Figure 1).

\section{Production of PHA's- PHB}

Many species of bacillus are known to produce PHB. The most studied are Alcaligenes eutrophus, Bacillus megaterium,
Methylobacterium rhodesianum, M. Extorquen, P. Putida, Sphaerotilus natans.

There are two kinds of bacteria. The bacterium that produces polymer under nutrient deficient condition comes under one group. The bacterium that produces polymer along with growth in the media [4].

\section{Media, growth conditions, fermentation}

Of all the different types of bacteria each one of them uses different kinds and different combinations of media source. Few examples for such combinations of carbon, nitrogen sources are methanol as carbon source, malate, acetic acid and n-alkanoic acid, Ammonium chloride, ammonium sulphate as nitrogen sources.

Media and media conditions play vital role for production of polymers. All the important factors carbon, nitrogen sources, $\mathrm{pH}$, temperature, pressure, media flow rate, oxygen supply (based on the process aerobic and anaerobic choosen) [5].

Cheap sources of media include molasses, cornsteep liquor, wheat bran, starch. Choosing a cheap source of media plays a major role in makes the production economical. Activated sludge and co-culturing systems are also known to be profitable based on the inoculum strains used [6].

\section{Product recovery}

After production the next crucial step in down streaming processing which should be taken care of for profitable $\mathrm{PHB}$ production is product recovery. Wide variety of methods are preferred for recovery of product like solvent extraction, enzymatic digestion, dispersion. Methods like centrifugation, filtration are applied with a subsequent use of solvents for extraction and product isolation.

Bacterial systems- individual bacteria producing PHB's can be

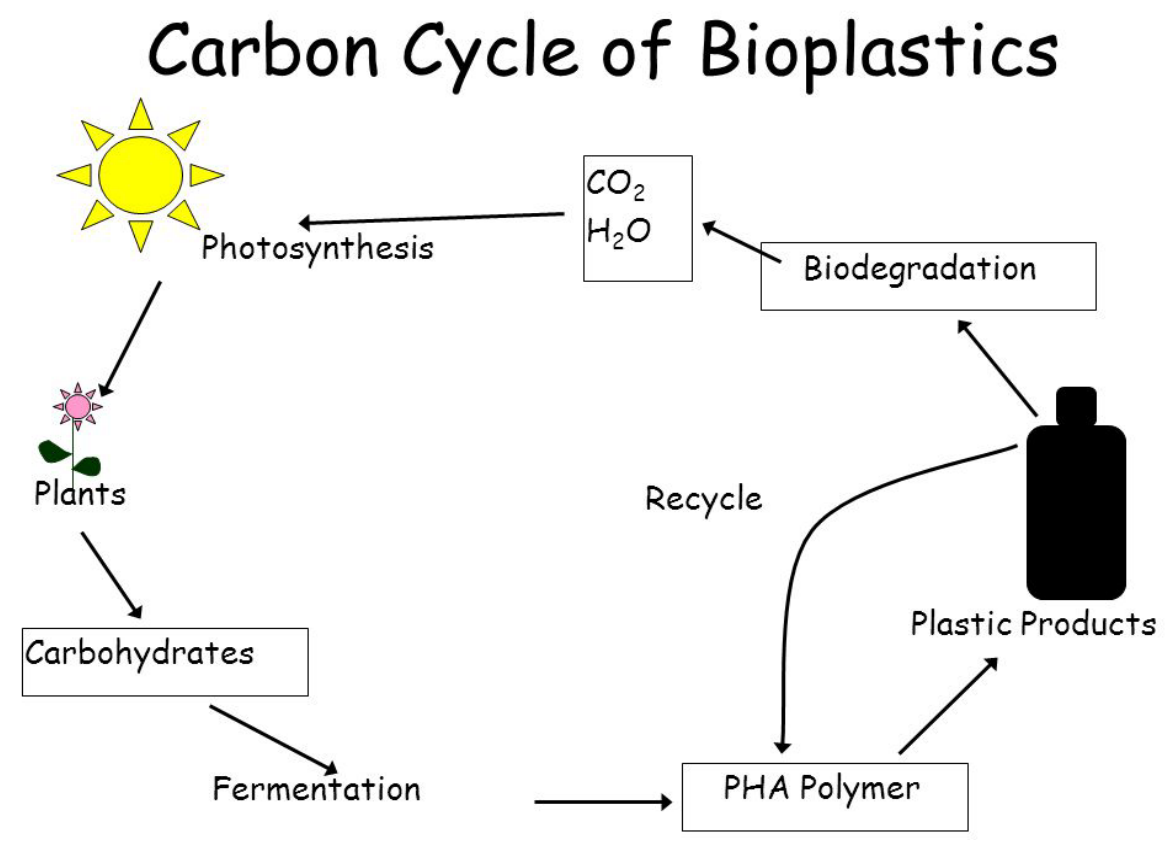

Figure 1: Carbon cycle of Bioplastics. 
Citation: Bharti SN, Swetha G (2016) Need for Bioplastics and Role of Biopolymer PHB: A Short Review. J Pet Environ Biotechnol 7: 272. doi:10.4172/2157-7463.1000272

used for profitable yield or recombinant bacteria can be utilized. The recombinant strains are genetically modified to give a good yield of product. Recombinant strains have many advantages over natural, like high cell density can be achieved in comparatively less time, inexpensive carbon source rather than enriched media can also be preferred which again makes the production profitable [7].

\section{Conclusions}

The main aim of this short review was to through light on Need for Bioplastics. Depending on cheap and renewable sources for bioplastics production rather than non renewable sources, since synthetic plastic not only cause harm to environment during their degradation also they deplete the natural resources, Commercialization of production process,

Factors affecting the production cost of PHB, where they can be brought down in compared to synthetic plastic.

Further studies on recombinant strains as well as profitable production and down streaming procedures during the production of PHB could be a promising biotechnological application paving way for this bio plastic in replacing the harmful synthetic plastic.

\section{References}

1. Ceyhan N, Ozdemir G (2011) Poly-hydroxybutyrate (PHB) production from domestic wastewater using Enterobacter aerogenes $12 \mathrm{Bi}$ strain. African Journal of Microbiology Research 5: 690-702.

2. Saharan BS, Sharma AS (2012) Bioplastics-For Sustainable Development: A Review. International Journal of Microbial Resource Technology 1: 11-23.

3. Madison LL, Huisman GW (1999) Metabolic engineering of poly (3-hydroxyalkanoates): from DNA to plastic. Microbiol. Mol. Biol. Rev. 63: 21-53.

4. Byrom D (1994) Polyhydroxyalkanoates In: Mobley DP, editor. Plastics from microbes: microbial synthesis of polymers and polymer precursors. Munich: Hanse.

5. Byrom D (1987) Polymer synthesis by microorganisms: technology and economics. Trends Biotechnol. 5: 246-250.

6. Saharan BS, Anita, Ranga P (2007) Studies on production of PHB using soil isolates from irrigated agro-ecosystems. In: Proceedings of 48th AMI Annual Conference of the Association entitled "Microbes: Biofactories of the future" held on $18^{\text {th }}-21$ st November, 2008 at Department of Biotechnology, Indian Institute of Technology Madras, Chennai.

7. Kumar BS, Prabakaran G (2006) Production of PHB (bioplastics) using bioeffluent as substrate by Alcaligens eutrophus. Indian Journal of Biotechnology 5: 76-79. 